\title{
AS REPERCUSSOES DO PIBID NA FORMAÇÃO INICIAL DE PROFESSORES: UMA REFLEXÃO A PARTIR DA TEMÁTICA INDÍGENA EM SALA DE AULA
}

\section{LAS REPERCUSIONES DEL PIBID EN LA FORMACIÓN INICIAL DE PROFESORES: UNA REFLEXIÓN SOBRE LA TEMÁTICA INDÍGENA EN EL AULA}

BATISTA, Vanessa Souza ${ }^{1}$

\section{RESUMO}

O presente artigo apresenta o planejamento, desenvolvimento e os resultados obtidos com o projeto "Diversidade e identidade indígena brasileira: uma abordagem entre o presente e o passado". Trata-se de uma das atividades realizadas pelo Programa Institucional de Iniciação à Docência (PIBID), da área de História da Universidade Federal de Alfenas (UNIFAL-MG). O projeto foi desenvolvido no primeiro semestre de 2015 , com alunos do $8^{\circ}$ ano do Ensino Fundamental e do $1^{\circ}$ e $2^{\circ}$ ano do Ensino Médio de uma Escola de Educação Básica da cidade de Alfenas-MG. O processo de elaboração das atividades até sua aplicação permitiu compreender a importância da experiência em sala de aula proporcionada pelo PIBID. Logo, o programa contribuiu para a melhor preparação dos licenciandos para a futura atuação na educação.

Palavras-chave: PIBID; Temática indígena; Formação inicial; Ensino Aprendizado

\section{RESUMEN}

En este artículo se presenta La planificación, desarrollo y resultados obtenidos con El proyecto "Diversidad e identidad indígenas de Brasil: una aproximación entre el presente y El pasado." Esta es una de lãs actividades llevadas a cabo por el Programa Institucional Introducción a La Enseñanza (PIBID), del área de Historia de La Universidad Federal de Alfenas (UNIFAL-MG). El proyectofuedesarrollado durante el primer semestre de 2015, con los Estudiantes del $8^{\circ}$ grado de laescuela primaria y $1^{\circ}$ y segundo año de laescuela secundaria de una escuela de Educación básica de laciudad de Alfenas-MG. El proceso de elaboración de lasactiidades hasta su aplicación permitió comprender La importancia de La experiência en el aula proporcionada por el PIBID. Asípues, el programa contribuyó a preparar mejor a los estudiantes para La acción futura en La educación.

Palabras clave: PIBID; Lascuestiones indígenas; La formación inicial; Enseñanzaaprendizaje.

\section{INTRODUÇÃO}

1Mestranda do PPGE da Universidade Federal de Ouro Preto (UFOP), Mariana, MG - Brasil. E-mail: vsouzabatista@gmail.com

Criar Educação, Criciúma, v. 6, n¹, julho/novembro 2016.- PPGE - UNESC 
O Programa Institucional de Bolsa de Iniciação à Docência (PIBID), de acordo com a Portaria $\mathrm{n}^{\circ} 72$ de 9 de abril de 2010, foi uma iniciativa para o aperfeiçoamento e a valorização da formação de professores para a educação básica. O PIBID possibilitava a inserção dos licenciandos no contexto das escolas públicas, desde o início da sua formação acadêmica. Para tanto, o programa oferecia bolsas distribuídas nas diversas áreas dos cursos de licenciatura, para alunos e professores da graduação, assim também como para professores da educação básica da rede pública. Por meio dessa parceria, entre a universidade e a escola, era possível o desenvolvimento de atividades didático-pedagógica, na qual o bolsista de Iniciação à Docência possuía a orientação de um docente da licenciatura e do professor da escola participante. Sendo, dessa forma, os principais objetivos do programa a valorização do magistério, contribuindo para elevara qualidade da formação inicial de professores nos cursos de licenciatura e promover a integração entre educação superior e educação básica (BRASIL, 2010).

O PIBID da área de História da Universidade Federal de Alfenas (UNIFAL-MG) teve início em 2011 com o desenvolvimento de atividades com duas escolas públicas da cidade de Alfenas-MG, reuniu 14 licenciandos subdivididos em dois grupos. Os números cresceram significantemente, no ano de 2015 eram dois coordenadores de área, quatro escolas públicas parceiras, com um supervisor em cada e a participação de 24 bolsistas de iniciação à docência. As atividades desenvolvidas pelo grupo perpassavam, além de uma carga horária na escola, encontros semanais com o coordenador e quinzenais com a supervisora. Nessas reuniões discutiam-se os projetos a serem implantados nas escolas, realizava-se a leitura e discussão de textos, quais contemplavam questões voltadas ao ensino aprendizado e também referenciais teóricos as propostas a serem desenvolvidos. Assim sendo, tornou-se um espaço que favorecia o debate e a troca das experiências vivenciadas na sala de aula.

No primeiro semestre de 2015 trabalhou-se, na subárea História do Pibid UNIFALMG, o projeto "Diversidade e identidade indígena brasileira: uma abordagem entre o presente e o passado". A proposta consistia em apresentar aos alunos a diversidade da comunidade indígena, apontando a ação desse grupo na história do Brasil e principalmente permitir uma reflexão sobre sua atuação e principais demandas no Criar Educação, Criciúma, v. 6, n¹, julho/novembro 2016.- PPGE - UNESC 
tempo presente. A partir da elaboração e desenvolvimento desse projeto foi possível identificar as contribuições que a experiência vivenciada como bolsista de iniciação a docência acarreta para a formação inicial de professores.

A fim de contemplar essas questões, o presente artigo foi estrutura em três partes. Primeiramente foi apontada a construção do projeto, como foi identificada a necessidade de trabalhar com a temática indígena, a sua justificativa e o referencial utilizado. Posteriormente, foi discutido o desenvolvimento das atividades nas salas de aula, os objetivos pretendidose a metodologia utilizada. Na terceira parte realizou-se uma discussão sobre os resultados obtidos com a aplicação do projeto, tendo como reflexão principal a identificação de como esse processo repercutiu na formação inicial de professores.

\section{A CONSTRUÇÃO DO PROJETO}

O ensino da temática indígena é garantido pela Lei $n^{\circ} 11.645$ de março de 2008, que estabelece a obrigatoriedade no ensino fundamental e ensino médio, do estudo da história e cultura afro-brasileira e indígena, com o intuito de abordar as etnias indígenas na formação da sociedade nacional, resgatando as suas contribuições na área social, econômica e política, pertinentes à história do Brasil. Mesmo com essa ressalva legal foi possível perceber, por meio da observação das aulas ministradas pela supervisora, análise do livro didático da escola e diagnóstico realizado com os alunos, que pouco sobre a temática era discutida na escola. Quando discutido, normalmente cabia ao índio à relação com o exótico e o congelamento de uma imagem relacionado ao século XVI.

A partir dessas constatações foi elaborado o projeto "Diversidade e identidade indígena brasileira: uma abordagem entre o presente e o passado" que teve como objetivo apresentar aos alunos a diversidade da população indígena, com o intuito de romper com a visão homogeneizada construída nos livros didáticos. Trabalhou-se em uma perspectiva de passado/presente, a fim de possibilitar a compreensão dos alunos sobre a atuação dos indígenas atualmente no Brasil, suas lutas e conquistas. Para tanto, optou-se por um foco nas etnias localizadas na região de Minas Gerais, aproximando a temática à vivência dos discentes.

Outra justificativa para essa proposta é que durante muito tempo, os indígenas foram considerados povos sem perspectiva histórica. Henri Moniot (1979) apresenta 
que a História, por um longo período, esteve restrita ao continente europeu. Todos os demais povos não eram considerados como possuidores de história, foram compreendidos como selvagens que não fizeram nada de notável, antes da chegada dos brancos e da civilização. Essas ideias e justificativas impediram que a curiosidade histórica tivesse espaço. Os poucos que se interessavam em trabalhar com essa temática apontavam a falta de fontes, pois os povos não-europeus não possuíam escrita e sua tradição oral não era considerada. Apenas no final do século XX foram mudadas as condições em torno das populações não europeias.

No Brasil, a historiografia cometeu vários esquecimentos e equívocos no que se refere ao indígena. Ao longo do século XX, como pontua José Freire (2010), os indígenas foram considerados como um bloco homogêneo, como se fossem uma só cultura. Concebeu-se uma ideia de um "índio autentico", que estava preso ao século $\mathrm{XV}$ e que não fazia parte da identidade brasileira. Assim também, associaram a imagem dos indígenas a povos atrasados, selvagens, entre outros estereótipos. Logo, se ignorou as diversidades de etnias, religião, línguas e a complexidade da cultura e das práticas sociais indígenas.

Henri Moniot (1979) ressalta que todas as sociedades que sofreram a dominação ocidental, total ou parcial, foram abaladas, modificadas, decompostas, inseridas nos ritmos unificadores de um história mundial. Porém, também foram atores, sujeitos de tomadas de iniciativa, de reestruturações, segundo modalidades e em conjunturas bastante variáveis. É possível distinguir as sobrevivências, as ressurgências após o processo colonial, os conservadorismos deliberados, os empréstimos impostos, as reinterpretações, as inovações. Para esclarecer corretamente as tendências que se esboçavam antes que o Ocidente as desviasse, as profundas continuidades e as verdadeiras rupturas, é necessário confrontar constantemente as épocas contemporânea, colonial e pré-colonial. Sendo cada uma, a sua maneira, um documento para as outras.

Nesta mesma perspectiva, John Manuel Monteiro (1995) aponta que cabe a história indígena no Brasil recuperar o papel histórico desses atores na formação das sociedades e culturas do continente. Sendo necessário reverter à omissão e a visão que os enquadra como vítimas de poderosos processos externos à sua realidade. Para o autor é preciso uma nova bibliografia, que contribua para ampliar a visibilidade dos povos indígenas, numa história que sempre os omitiu, como também Criar Educação, Criciúma, v. 6, n¹, julho/novembro 2016.- PPGE - UNESC 
revelar as perspectivas destes mesmos povos sobre seu próprio passado, incluindo visões alternativas do contato e da conquista.

A partir dessas discussões foi possível elaborar o projeto considerando a figura do indígena como sujeito histórico. Ressalta-se que são povos presentes na sociedade brasileira atualmente e que por meio de novas formas de expressão política, tais como as organizações indígenas, reivindicam e reconquistam direitos históricos. Consequentemente, uma das discussões importante a realizar-se com os alunos foi sobre o movimento indígena. Pois esses povos apresentam um conjunto de resistências que correspondem a um processo longo, ora de enfrentamento, de caráter físico e cultural assumindo, segundo Rosa Helena Dias da Silva (2000), ora de relacionamento, utilizando a diplomacia. Segundo a autora, seus direitos conquistados são resultado de muita luta. Enquanto povos diferenciados, os indígenas buscaram construir relações de interação com a sociedade e o Estado, para que assim pudessem efetivar a "cidadania indígena".

Além de abordar a diversidade e a resistência dos grupos indígenas ao longo do processo histórico buscou-se no planejamento das aulas, maneiras de expor aos alunos que trabalhar a temática indígena exige o respeito ao outro, ao diferente. Como Nestor Garcia Canclini (2005) apresenta, é necessário averiguar como culturas diferentes coexistem, chocam ou se ignoram a cultura comunitária. Partindo da perspectiva da interculturalidade é necessário prestar atenção às misturas que vinculam os grupos, considerando as diferenças e as fusões. Sendo dessa forma, a finalidade do projeto, a interferência na realidade do aluno para que se compreenda e reflita a importância de respeitar a identidade indígena.

\section{O DESENVOLVIMENTO DAS ATIVIDADES}

As atividades foram desenvolvidas no primeiro semestre de 2015 com alunos do $8^{\circ}$ ano do ensino fundamental, $1^{\circ}$ e $2^{\circ}$ ano do Ensino Médio, tiveram duração de três meses, sendo uma aula semanal em cada sala. O projeto consistiu em três etapas, primeiramente foi realizado um diagnóstico inicial para compreender as principais representações dos alunos sobre os indígenas. A partir do que foi apresentado por eles foi construída quatro aulas expositivas. Posteriormente, na terceira etapa, os 
alunos foram separados em grupos e se sugeriu que eles produzissem um material para apresentar aos colegas.

O diagnóstico inicial aconteceu em dois momentos. Primeiramente foi feita a seguinte pergunta aos alunos: "Quando vocês pensam em 'indígenas', quais as primeiras ideias que surgem na cabeça de vocês?" Tudo que os alunos disseram foi escrito no quadro e eles anotaram as palavras no caderno. Em um segundo momento, os alunos receberam uma folha com quatro imagens, todas elas continham indígenas em diferentes situações, na escola, trabalho, faculdade e um jogador de futebol. A ideia era que os alunos construíssem um texto a partir da análise das imagens. Mais nenhuma informação foi dada, para não intervir na representação que os alunos continuam do indígena e que deveriam aparecer no texto.

Ao realizar tal diagnóstico inicial, o propósito era identificar o conhecimento prévio dos alunos sobre os indígenas. Para tanto, os alunos não tiveram nenhuma informação sobre a temática, buscou-se que eles expressassem, seja na forma oral, seja na forma escrita, suas representações sobre esses povos. Tendo como referencial Lev Vygotsky (1977) considerou-se que a aprendizagem não se inicia na idade escolar, mas muito antes dessa e para o melhor desenvolvimento das atividades seria imprescindível partir do que os alunos já sabiam sobre o assunto. Mesmo que o conhecimento dos discentes fosse baseado em estereótipos, a partir deles seria possível propor uma abordagem que possibilitasse um novo entendimento sobre os povos indígenas.

Como resultado do diagnóstico, as primeiras associações ligadas à imagem dos indígenas feitas pelos alunos foram: flecha, dança da chuva, pintura facial, ritual, aldeia, pena, Amazonas, não usam roupa, mandioca, peixe. De um modo geral, percebeu-se que os discentes possuíam uma dificuldade em pensar "o que significa ser índio no Brasil", não conseguiram compreender a organização indígena sem utilizar os padrões da sociedade em que viviam. O mesmo foi reforçado na produção dos textos, em que uma grande parcela dos alunos apresentou a dicotomia entre progresso/pobreza. Eles compreenderam os índios como pobres que precisavam sair de suas aldeias para ir estudar, trabalhar, depois voltar para ajudar aos demais. Houve também uma forte ideia de falta de vestimenta e que dentro da comunidade 
indígena existia uma hierarquização. Alguns expressaram uma idealização do índio, como um exemplo a ser seguindo, pois mantém um forte contato com a natureza.

O diagnóstico confirmou que, como apresenta Eduardo Viveiros de Castro (2006), existe uma visão estereotipada do índio com cocar de penas, arco e flecha e isolado na floresta. O autor aponta que é necessário discutir e compreender, que o índio é um membro pertencente a uma comunidade indígena, que é constituída com as relações de parentesco ou de vizinhança, por meio de laços histórico-culturais. É parte de um estado de espírito, de "um modo de ser e não um modo de aparecer" (p.03), independe do índio que vive isolado ou do índio que teve contato intermitente. Tais questões foram consideradas para se pensar o desenvolvimento das demais atividades, com o objetivo de romper as representações homogeneizadoras dos alunos.

A partir do que os discentes apresentaram foi planejado quatro aulas expositivas que contemplasse as principais questões apontadas no diagnóstico inicial. Em uma perspectiva de presente e passado buscou-se abordar temáticas relacionadas à resistência indígena, a diversidade dos povos e as suas principais demandas atuais, pautando o movimento indígena e questões como a demarcação de terras.

A primeira aula consistiu em realizar uma discussão sobre a diversidade indígena. Em um primeiro momento foi feita a leitura das palavras que os alunos apresentaram no diagnóstico. Posteriormente, assistiram ao vídeo da série Índios no Brasil "Quem são eles?" Pediu-se para que os alunos observassem o vídeo pensando as palavras lidas e apresentadas por eles. Na última etapa da aula realizou-se uma discussão, a intenção era considerar até que ponto as ideias apontadas pelos discentes, tais como: "índio é tudo igual", "não tem celular", "não vaia escola" e demais estereótipos, de fato, se sustentavam em meio a diversidade da comunidade indígena brasileira. O vídeo permitiu compreender a diversidade tanto nas formas de vestir, comportamento, como na língua e na cultura, sendo inviáveis generalizações. Na segunda aula trabalhou-se duas músicas: "EjuOrendive" do grupo de rapBrôMc's, composta por integrantes Guarani Kaiowá, e "A vida é desafio" do grupo Racionais Mc's. Considerando Arnaldo Contier (2005) que aponta que o rap é uma forma de resistência as diferentes formas de desigualdade e exclusão social presentes na sociedade brasileira. Pretendeu-se apresentar a apropriação dos indígenas do rap, como uma forma de denúncia e luta. Além de ouvir as músicas realizou-se a leitura Criar Educação, Criciúma, v. 6, n¹, julho/novembro 2016.- PPGE - UNESC 
das letras, com o propósito de evidenciar aos alunos as reinvindicações desses grupos distintos. Pois, como reforça Geni Rosa Duarte (1999) a condição do excluído é um forte ponto no discurso do Rapper e surge como um objeto de reflexão e denúncia.

$\mathrm{Na}$ terceira aula foi discutido sobre a demarcação de terras indígenas, com a exibição do vídeo "Nossas Terras", da série Índios no Brasil. O intuito da aula era possibilitar a compreensão dos alunos, sobre o processo legal de aprovação da posse da terra indígena, apresentando os órgãos governamentais importantes para os índios, tal como a Fundação Nacional do Índio (FUNAI). Realizou-se também uma análise das leis envolvidas na demarcação de terras, principalmente a Constituição Federal de 1988 e o Estatuto do Índio. Posteriormente, na quarta aula, disponibilizou-se para os alunos duas reportagens sobre o movimento indígena, uma da década de 1980 e outra de abril de 2015, a fim de abordar as principais demandas do grupo nos últimos 35 anos. Foi feita a leitura das reportagens e posteriormente os alunos responderam um questionário, que foi utilizado para averiguar a apropriação deles sobre a temática abordada.

Após essas aulas, de caráter mais expositivo, pensou-se em finalizar o projeto abrindo espaço para o protagonismo dos alunos em um trabalho em equipe. A finalidade dessa atividade seria aprodução de materiais didáticos pelos alunos, para futura apresentação aos colegas do tema discutido. Nessa perspectiva pedagógica considerou-se como referencial Maria Teresa Mantoan (2001), que aponta que o trabalho em equipe é um método que possibilita a cooperação, estimula os alunos a compartilharem saberes e habilidades, além de desenvolverem autonomia. Pois por meio do trabalho coletivo e diversificado os alunos teriam liberdade para a discussão e para escolher uma abordagem específica sobre a temática indígena.

Para tanto, na terceira etapa,em cada uma das salas, os alunos foram divididos em três grupos, cada um ficou com uma etnia indígena de Minas Gerais: Maxacalí, Pataxó e Krenak e uma bolsistas de iniciação a docência responsável. O intuito era romper com a ideia da existência de uma mesma cultura indígena, possibilitando o contato dos alunos com um povo específico. Tais atividades se desenvolveram em três aulas, nas quais os discentes estiveram fora da sala. Os grupos se reuniram na quadra esportiva da escola, por ser um espaço amplo que possibilitava a melhor organização das equipes para a discussão e produção de materiais.Como cada 
grupo trabalhou com uma etnia diferente a última aula do projeto seria para a apresentação de cada uma das equipes.

\section{RESULTADO E DISCUSSÃO}

Inicialmente os alunos mostraram-se resistentes à temática indígena. Alguns demonstraram incomodo com a presença de pibidianos na sala e com a temática escolhida, "Pibid de novo? Falar de índio? Por que não falam de outra coisa?" (alunos do $8^{\circ}$ ano). A partir dessa fala foi necessário refletir sobre o projeto elaborado. Percebeu-se que o tempo de três meses era muito extenso e também eram necessárias adaptações e modificações conforme as particularidades de cada sala.As mesmas atividades para três turmas totalmente distintas $\left(8^{\circ}, 1^{\circ}\right.$ e $2^{\circ}$ do Ensino Médio), não estavam funcionando. Várias questões foram melhores trabalhadas e aprofundadas com as turmas do Ensino Médio, enquanto no $8^{\circ}$ ano, por ser uma sala mais infantilizada, eles preferiam atividades que envolvessem colorir e desenhar, o que levou a adaptar algumas aulas.

Destaca-se que em uma das aulas sobre o processo de demarcação de terras, no $1^{\circ}$ ano do Ensino Médio, as discussões foram conduzidas pelos próprios alunos. Alguns se posicionaram contrários ao processo de demarcação, considerando-o injusto, uma das alunas disse: "Eu não concordo com isso! Pois se eu tenho uma terra que comprei com meu dinheiro, tenho que sair de lá por que os índios querem ela? Eu acho errado!". Esses posicionamentos contribuíram para o desenvolvimento da aula, pois os alunos expressaram o que realmente pensavam e foi a partir disso que se buscou romper com essa visão. Para tanto, apresentou-se aos alunos uma nova forma de compreender esse processo, fundamentadas nas relações históricas entre indígenas e não indígenas sobre o direito a terra no Brasil. Dessa forma, como apontado por Valesca Giordano Litz (2009) esse processo de ensino e aprendizagem teve como principal objetivo o desenvolvimento e aprofundamento da criticidade dos alunos.

Para além da relação com a escola e os alunos, é necessário ressaltar que o projeto, desde sua elaboração até sua finalização, exigiu muito estudo por parte dos bolsistas de iniciação a docência. Foram necessárias muitas leituras, organização de seminários e discussões com professores que trabalhassem especificamente com a 
temática indígena. Durante seu desenvolvimento os alunos trouxeram novas questões, consequentemente essas demandas mobilizaram novas reflexões sobre a temática e sua forma de trabalho no espaço escolar. A aplicação do projeto também possibilitou perceber que o preconceito e o estereótipo formado sobre o assunto não acabaram simplesmente por que foi feita uma discussão. A experiência no PIBID permitiu compreender que esse é um processo lento, que às vezes se vê poucos resultados imediatos.

Destaca-se que também é possível identificar alguns acertos. A aula que discutiu a música "Eju Orendive" do grupo BrôMc's, foi um sucesso. O que a princípio gerou um estranhamento, foi o caminho que viabilizou que os alunos rompessem com ideias estereotipadas sobre os indígenas, compreendendo tratar-se de um grupo diversificado. Segundo Sandra Santos (1999) o Rap como um recurso didático ainda é pouco utilizado, uma vez que há preconceito e estereótipos relacionados a esse estilo musical com o uso de drogas e a violência. As críticas de muitos profissionais em relação a esse recurso nas salas de aula são inegáveis, porém, a autora destaca que estudos apontam que nas escolas em que o Rap foi utilizado como recurso didático houve uma identificação significativa por parte dos alunos. Foi possível identificar uma aproximação dos discentes ao compreender a própria história, se tornando uma ferramenta para elucidar a criatividade e também o caráter crítico dos mesmos. Essa consideração se faz necessária, pois, de fato, foi o que aconteceu na aplicação da atividade referente à temática indígena.

Outra consideração pertinente trata-se de ressaltar a importância e a dificuldade em não se trabalhar com aulas expositivas. Na terceira etapa, em que os alunos se reuniram em equipe para produziram materiais, foi muito desafiador trabalhar fora do ambiente da sala de aula. Houve alguns casos de indisciplina, sendo muito difícil manter o controle e o foco nas atividades a serem desenvolvidas. $O$ trabalho em equipe também foi comprometido em algumas salas. Os alunos apresentaram relativa dificuldade em tomar iniciativa enquanto grupo para produzir algo, demonstrando talvez, o pouco espaço que possuem na sala de aula para a participação efetiva nas atividades. Para além dessas dificuldades, foi possível perceber um engajamento de alguns alunos, que se esforçaram em refletir sobre a temática e buscaram a produção de materiais. Como resultados finais do projeto 
foram produzidos duas maquetes, uma da aldeia Krenak e outra da aldeia Maxacali, dois vídeos sobre essas aldeias e cartazes sobre os Pataxó.

Após a execução do projeto todos saíram transformados, alunos, professores e bolsistas de iniciação a docência. Mesmo que os estereótipos não acabaram de imediato, um movimento teve início, possibilitando uma reflexão sobre os povos indígenas, principalmente os presentes no estado de Minas Gerais.E dentro de um propósito maior, o projeto possibilitou ressaltar a importância de conhecer outra cultura.

\section{CONSIDERAÇÕES FINAIS}

O projeto sobre os povos indígenas encontrou resistências por parte dos alunos, mostrou-se falho em alguns aspectos e nenhuma aula saiu exatamente como planejada. Tais erros e dificuldades são inegáveis, porém, além disso, foi possível identificar resultados muito positivos referentes à compreensão dos alunos sobre a temática. Na maior parte das aulas os discentes se mostraram participativos, contribuíram em muitas discussões, mesmo que embasados em um conhecimento estereotipado, tais posicionamentos foram à força motriz que proporcionaram reflexões mais aprofundadas. Destaca-se também a importância de se aproximar a temática a vivencia dos alunos, o que aconteceu ao se trabalhar com povos indígenas situados da região de Minas Gerais, gerou um interesse e uma significação maior aos discentes.

Os imprevistos e erros exigiram dos bolsistas de iniciação a docência rever constantemente a finalidade da proposta. Foi necessário ao longo do semestre repensar as aulas, considerar as particularidades de cada sala, assim também a forma das atividades e a maneira de lidar com os alunos, foi preciso se reinventar constantemente. Todo esse processo ressalta a importância da experiência em sala de aula, os transtornos, erros e acertos, só foram possíveis de serem identificados com o desenvolvimento diário do projeto. Estar em sala de aula, lidar com os alunos, compreender a organização da escola configurou-se como um espaço de grande conhecimento e amadurecimento profissional. Disso, ressalta-se a importância do PIBID enquanto proporcionador dessa experiência. 


\section{CRIAR EDUCAÇÃO}

Revista do Programa de Pós-Graduação em Educação - UNESC

De fato, a análise do desenvolvimento desse projeto permitiu compreender o alcance dos objetivos pretendidos pelo PIBID. A integração entre educação superior e educação básica ocorreu de várias formas, rompendo com a imposição da primeira sobre a segunda. O projeto nasceu de uma demanda da escola e foi elaborado em parceira entre supervisora, licenciandos e coordenador de área, o que criou um espaço de trocas de experiências e aprendizagens. Desenvolver as atividades, identificar os resultados positivos consolidou-se como um grande incentivo a docência e a valorização do magistério, elevando a qualidade da formação inicial de professores nos cursos de licenciatura.

Criar Educação, Criciúma, v. 6, n¹, julho/novembro 2016.- PPGE - UNESC 


\section{CRIAR EDUCAÇÃO}

Revista do Programa de Pós-Graduação em Educação - UNESC

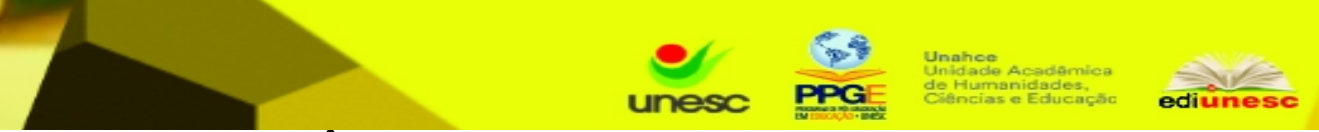

\section{REFERÊNCIAS}

BRASIL.Coordenação de aperfeiçoamento de pessoal de nível superior. Portaria $\mathrm{N}^{\circ}$ 72, de 9 de abril de 2010. Dispõe sobre o Programa Institucional de Bolsa de Iniciação à Docência - PIBID, no âmbito da CAPES. Diário Oficial da União, Brasília, p.26-27, abr. 2010.

CANCLINI, Nestor Garcia. Diferentes, desiguais e desconectados: mapas da interculturalidade. Rio de Janeiro: UFRJ, 2005.

CASTRO, Eduardo Viveiros de. No Brasil, todo mundo é índio, exceto quem não é. In.: RICARDO, Beto; RICARDO, Fany (org.). Povos indígenas no Brasil: 20012005. São Paulo: Instituto Socioambiental, 2006. p. 41-49.

CONTIER, Arnaldo Daraya. O rap brasileiro e os Racionais MC's. In: SIMPOSIO INTERNACIONAL DO ADOLESCENTE, 1, 2005, São Paulo. Proceedings online... Disponível em:<http://www.proceedings.scielo.br>. Acesso em: 18 de março de 2015.

DUARTE, Geni Rosa. A arte na (da) periferia:sobre...vivencias. In.:ANDRADE, Elaine Nunes de (org.). Rap e Educação. São Paulo: Selo Negro, 1999.p. 13-22.

FREIRE, José Ribamar Bessa. A herança Cultural Indígena, ou cinco ideias equivocadas sobre os índios. In: ARAÚJO, Ana Carvalho Ziller de (org.). Cineastas Indígenas, um outro olhar: guia para professores e alunos. Olinda: Vídeo nas Aldeias, 2010.

LITZ, Valesca Giordano. O uso da imagem no ensino de história. Universidade Federal do Paraná, Caderno Temático do Programa de Desenvolvimento Educacional do Estado do Paraná - PDE. Curitiba, 2009.

MANTOAN, Maria Teresa Eglér. Todas as crianças são bem-vindas a Escola.Revista Profissão Docente, mai./ago. 2001, vol. 1, no. 2, p. 1-19.

MONIOT, Henri. A História dos povos sem história. In.: LE GOFF, Jacques; NORA, Pierre (org.). História: novos problemas. $2^{a}$ ed. Rio de Janeiro, 1979. p. 99-112.

MONTEIRO, Jonh Manuel. O desafio da história indígena no Brasil. In.: SILVA, Aracy Lopes; GRUPIONI, Luis Donizete Benzi (org.). A temática indígena na escola. Brasília: MEC/MARI/ UNESCO, 1995. p..221-236.

SANTOS, Sandra. Alunos, estes desconhecidos. In.:ANDRADE, Elaine Nunes de (org.). Rap e Educação. São Paulo: Selo Negro, 1999. 


\section{CRIAR EDUCAÇÃO}

Revista do Programa de Pós-Graduação em Educação - UNESC

SILVA, Rosa Helena Dias da. Movimentos indígenas no Brasil e a questão educativa: relação de autonomias, escola e construção de cidadanias. Revista Brasileira de Educação,jan./abr. 2000, vol.1, no.35, p. 95-112.

VYGOTSKY, Lev S. Aprendizagem e desenvolvimento intelectual na idade escolar In: LURIA et al. Psicologia e pedagogia I : bases psicológicas da aprendizagem e do desenvolvimento. Lisboa : Estampa, 1977. p.103-117. 